\section{Summary of: The effect of veneers on cosmetic improvement}

S. Nalbandian ${ }^{1}$ and B. J. Millar²

\begin{tabular}{l} 
FULL PAPER DETAILS \\
\hline 'Prosthodontic Practice, Designer Smiles®, 17 \\
Gerard Street, Cremorne, Sydney, Australia; ${ }^{2 *}$ Senior \\
Lecturer/Honorary Consultant in Restorative Den- \\
tistry, Primary Care Dentistry, King's College London \\
Dental Institute at Guy's, King's College \&t St. Tho- \\
mas' Hospitals, Caldecot Road, London, SE5 9RW \\
${ }^{*}$ Correspondence to: Dr Brian J. Millar \\
Tel: +44 (0)20 7346 3585; \\
Fax: +44 (0)20 7346 3826 \\
Email: brian.millar@ kcl.ac.uk \\
Online article number E3 \\
Refereed Paper - accepted 5 February 2009 \\
DOI: 10.1038/sj.bdj.2009.609 \\
'British Dental Journal 2009; 207: E3
\end{tabular}

\begin{abstract}
Objectives This clinical study was designed to compare the patient's opinion of the cosmetic improvement after the placement of direct composite and indirect porcelain veneers. Methods This retrospective study involved a survey of 145 patients (96 responses) each treated with 10 direct composite (Vitalescence) or 10 porcelain (Fortress) veneers. Patients subjectively evaluated multiple aspects of their smile using visual analogue scales before and after treatment for colour, shape, size, smile line and overall facial appearance. Results There were no statistical differences between the cosmetic improvement achieved for porcelain and composite $(p \geq 0.05)$. Cost factors were not significant. Significant factors were: tooth conservation ( $p \leq 0.021)$, time ( $p \leq 0.012)$, repair costs ( $p \leq 0.009)$ and replacement costs $(p \leq 0.024)$ and favoured the direct composite veneers over the porcelain veneers. Correlation findings relating to what patients feel as the key components of the smile for overall cosmetic improvement showed medium to high correlations $(0.301 \leq r \leq 0.718)$ with tooth shape, colour and level of tooth display, gingival level, gingival symmetry and tooth whiteness. Conclusion The choice of material (direct composite resin vs porcelain) when constructing maxillary anterior veneers does not significantly affect the patient's perception of cosmetic improvement. However, there was a preference towards accepting the composite veneer option. Overall aesthetic satisfaction is multifactorial. The results support the opinion that the more conservative composite veneers are justified and that, given the choice and information, patients may prefer this option.
\end{abstract}

\section{EDITOR'S SUMMARY}

Patient understanding of treatment options is a necessary step in obtaining meaningful consent for any planned procedures, and all of us are, or should be, fully aware of this requirement. The dilemma that often arises however is the extent to which possible detrimental effects, or what may be regarded as negative aspects, should be expanded upon. In this study the description of the biological cost of tooth tissue removal in order to create porcelain veneers was explained to patients and contrasted with the lesser impact in this respect of direct composite restorations. As a result, many patients opted for the latter even though they understood that this modality may involve more, repeat or replacement treatment in the future compared to the indirect option.

of particular interest is that whichever alternative the patients chose, their satisfaction with the result was high and the authors speculate that this may be due to their fuller involvement in the decision-making process. This lends support to the frequently found situation with complaints in which the problem revolves around patient expectations not being met. In many cases the technical competence is not in question, rather it is that the eventual aesthetic outcome does not live up to the initial 'promise'. While this may be due to misunderstanding as much as miscommunication, in the early stages of treatment planning any procedure which lends clarity has to be welcome.

These findings are likely to have growing significance as disease levels continue to fall and the proportion of aesthetic operative treatment increases. This also has to be coupled with increasing patient knowledge of modern operative techniques through the internet and other media and a keenness and a desire to be better informed, often described as consumer power but perhaps more correctly regarded as an engaged selfawareness.

Although individual practitioner preference is also a consideration in these situations and not everyone is comfortable with using composites as direct restorations, they can provide optimal aesthetics with minimal or no tooth intervention, immediately improving aesthetics while leaving options for future orthodontic and restorative care.

The full paper can be accessed from the $B D J$ website (www.bdj.co.uk), under 'Research' in the table of contents for Volume 207 issue 2.

Stephen Hancocks, Editor-in-Chief

DOI: 10.1038/sj.bdj.2009.635 


\section{TO ACCESS THE BDJ WEBSITE TO READ THE FULL PAPER:}

- BDA members should go to www.bda.org

- Do not login on the BDA home page, if you are already logged in, please log out

- Then, in www.bda.org click on the link to the BDJ in the top left of the screen. A new window will open. If a new window fails to open please check the settings of any pop up blocker software that you have installed on your computer.

- You will now be asked to login with your BDA website login details which are on your BDA membership card.

- Once your details have been entered you will be transferred to the BDJ website. If your login does not work please contact the BDA Membership Department on 02075634550.

- If you are not able to access the article on the BDJ website there may be an issue with your system's firewall. If so, return to the BDA homepage and click on the link 'BDJ access problems' and follow the step by step guide.

\section{COMMENT}

This article deals with timely issues in aesthetic dentistry: patients' self-assessment of cosmetic improvement and the choice of restorative material and technique to fabricate anterior veneers.

Despite the potential bias and limitations of such a study mentioned by the authors, there are crucial findings shared with the reader, of which the first is a confirmation of patients' satisfaction and acceptance of direct techniques. In fact, the relatively strong economy which prevailed during the last decades has enabled an increasing number of patients to seek and afford elective dental treatments, which unfortunately pushed many professionals into the 'easiest' way, using indirect restorations to fulfil their 'customer' expectations. It is fully true that the placement of direct veneers requires skills and experience, but their tremendous advantage in term of tissue conservation is worth the effort for both the patient and practitioner. And last but not least, composite restorations can be easily repaired and maintained.

Finally, as pointed out by the authors, a dilemma lies sometimes in the information pertinence and objectivity shared with our patients. It is extremely satisfactory to realise that they will readily choose the conservative option, without any direct relation to the treatment cost, when properly informed. Many other aspects and conclusions of this article should also draw our attention, such as the decisional parameters for aesthetic treatments which really matter for our patients.
The information provided in this article converges with the results of other studies dealing with the use of conservative, adhesive techniques for the treatment of severe abrasion and erosion cases, where composite has also shown its excellent potential and behaviour. It is therefore refreshing to see, in addition, confirmation of the aesthetic potential of direct composite veneer for a 'cosmetic' procedure, traditionally devoted to the use of porcelain. The world is changing, sometimes for the better!

D. Dietschi, D.M.D, PhD, Privat-Docent University of Geneva, Switzerland and CASE University, Cleveland, USA
IN BRIEF

- Evolution of composite materials means that ceramic veneers are not always the best option.

- Most cases for composite veneers are accomplished in one visit with a minimum of tooth intervention.

- Direct composites allow us to plan for the future and make appropriate changes if and when required. The results with composite can be as good as ceramic.

\section{AUTHOR QUESTIONS AND ANSWERS}

1. Why did you undertake this research? Advances in bonding technology and composite materials have given dentists an opportunity to carry out aesthetic changes to teeth with less destruction. Most cases are accomplished with minimum or no tooth intervention, no local anaesthesia, and at a reduced cost to the patient in one visit. However, many clinicians do not offer this treatment option and favour the more invasive porcelain veneers. In the past 10 years we have seen an explosion in cosmetic dentistry, where indiscriminate amounts of tooth structure are sacrificed for cosmetic improvement. This research was carried out to investigate patients' attitudes to the level of improvement they receive with composite and porcelain veneers as well as their preference for either modality.

2. What would you like to do next in this area to follow on from this work?

We would like to educate dentists to be able to carry out the clinically challenging placing of composite veneers that will satisfy their patients as much as the easier technique of bonding porcelain veneers. The evidence from this research can be used to encourage clinicians to embark of training programmes to become skilled in the aesthetic use of composite. The fully trained clinician will give their patients unbiased choice. We also aim to test the extended use of composite resin and fibre-bonded technology in contingency planning, occlusal treatments, treatment of tooth wear, as an assessment tool, and in the treatment of aesthetically and functionally complex cases. 